\title{
Application of digital solutions in the physical culture and sports industry as an element of sustainable regional development
}

\author{
Anastasia Aleksina ${ }^{1, *}$, Olga Kazakova ${ }^{2}$, and Anton Aleksin ${ }^{2}$ \\ ${ }^{1}$ Samara State University of Economics, Samara, Russia \\ ${ }^{2}$ Samara National Research University named after academician S. P. Korolev, Samara, Russia
}

\begin{abstract}
It is necessary to note the importance of digitalization of the industry, which is necessary and possible to solve with the help of digital services and platforms with the support of the state. The paper presents the results of the analysis of scientific works and the materials of strategic sessions on the development of new digital solutions, implying a platform approach to the management of the field of physical education and sports services. The analytical module of the platform will allow the collection and interpretation of industry data on economic, social and sports indicators, including the use of the artificial intelligence technology. The prospects of using the ecosystem of the information and service platform in the implementation of various federal programs in the field of physical culture and sports are revealed. The results of monitoring of digital technologies for physical education and sports education in two leading universities of Russia are presented. Analysis of Sensor Tower service statistics on the number of downloaded mobile sports applications was carried out. The foreign experience of introduction of digital technologies on the example of sports commercial organization (MLBAM) is presented. Priority directions of using digital solutions in sports industry are defined, thanks to which, on the basis of objective data, it will be possible to determine the popularity of certain sports among those involved, objectively and transparently evaluate state investments in sports and their performance.
\end{abstract}

\section{Introduction}

One of the main components influencing the processes of socio-economic transformation in the country is the regional factor. The sustainable development of the region is its ability to withstand various types of influences, to quickly return to its original state in case of disruption, or to achieve a higher point of development, as well as a steady improvement in the quality of life of the population. Thus, the sustainable development of the region cannot be imagined without the use of digital technologies in the socio-economic sphere.

\footnotetext{
${ }^{*}$ Corresponding author: ms.anastasia1992@mail.ru
} 
The development of the institution of human potential, as a factor in the socio-economic development of the region, is accepted as an axiom that does not require evidence. One of the basic foundations of such human development is physical culture and sport.

The development of physical culture and sports affects the growth of economic activity of the population, which in turn provides high labor productivity, activates the processes of accumulation and growth of knowledge, and therefore the growth of income in the economy of the region and the country as a whole.

Thus, the application of innovative digital solutions in the physical culture and sports industry is almost in demand at the regional level.

The digital transformation of physical culture and sports means not only the development and implementation of technical solutions, but also a huge amount of related work: conducting scientific research, eliminating legislative barriers, training and developing user competencies. Its success requires close cooperation between various ministries and departments, non-state organizations, regional authorities and sports federations [3].

It is evident that scientific progress affects all spheres of society. Thanks to it, it becomes possible to use digital technologies, including in the sports field. In the end of 2020, the Ministry of Sports of Russia gave the best digital solutions in the sphere of physical culture and sports. Concern about this problem even by state structures indicates the high relevance of the topic. Also in October 2020, the American publisher Forbes published an article describing the impact of the pandemic on digital changes in sports. Given that this topic is raised by both reputable publishers and government agencies, we should expect the active use of electronic technologies in the daily life of sports in the near future.

This article is based on research works of the authors Skarzhinskaya E.N., Sarafanova E.V. [13], Kazakova O.A., Ivanova L.A., Martynenko V.S. [6], Kukushkin A.A., Novoselov M.A. [8], Mantulenko V.V. [9], statistical data from the Sensor Tower platform [11], and resolutions of the Ministry of Sports of Russia [10] and others.

Understanding the existing capabilities of technologies in the field of physical culture and sports will help to improve and optimize all levels of the industry, from increasing the availability of training to improving the level of service provision by sports organizations. It is also important to understand what processes are slowing down the digital transformation of the physical culture and sports industry in order to determine how to further optimize them. The use of digital technologies at the state level will provide an opportunity for the state to monitor the health of citizens. This paper aims to offer up-todate digital solutions that will result in the development of the physical culture and sports industry in Russia and abroad.

\section{Methodology}

During the study, the following materials and methods were used to understand the general problem:

- The search analysis of regulatory and legal documents that regulate the use of information technologies in the activities of various sports organizations and institutions.

- Using Sensor Tower service statistics (which is formed from the analysis of data from the App Store and Google Play) to investigate interest in sports initiatives carried out using mobile applications in work.

- Application of induction and deduction methods, generalization for integrated study of opportunities in the field of innovations in sports industry for commercial sports organizations.

- Analysis of innovations that are widely used in: 
- introduction of digital systems which main goal is simplification of work with documents and reports automates processes of analytics at the expense of the centralized collecting statistics of training and competitive activity [1],

- creating an open ecosystem of digital platforms,

- development of online streaming platforms.

\section{Results}

In February 2020, a strategic session was held, following which the formed proposals were sent to the Presidential Council for the Development of Physical Culture and Sports for inclusion in the concept of "Strategies for the development of physical culture and sports for the period until 2030." The best digital solutions announced during this event should be noted as follows [15]:

Creation of an open ecosystem of digital platforms (a platform with services for managing sports infrastructure, a platform with services for citizen sports and health, a platform with services for sports events, a platform with services for sports public organizations, a platform with services for accelerating small and medium-sized enterprises in sports).

- Creation of active digital profiles of citizens in Russia integrated with the "Gosuslugi" system. Such a profile should be formed in preschool age and immediately include a person in the national sports rating (NSR). Changes in the digital rating due to the occupation of motor activity, participation in amateur sports events, professional sports allow a person to be awarded social and material bonuses from the state or commercial partners.

In late May, early June 2020, the Ministry of Sports of Russia prepared and approved a departmental digital transformation plan, which includes a strategy for the development of sports industry for a decade to come - up to 2030. The digital transformation presented the following principles: application of the registry model, extraterritoriality, support of domestic startups.

- The initiatives described above were first presented as projects, but have now gained state support. All of them are carried out to optimize the work of sports organizations and increase the interest of the population in sports activities. The creation of automated information systems (for example, "LSPORT") will greatly simplify the formation of documents and statistical reports. The introduction of online booking and registration systems for sporting events (such as FindSport) will make visiting sports and physical culture facilities more accessible. The introduction of digital platforms that combine a register of coaches and athletes will increase the quality of services provided. The created interactive map of sports institutions in the region will simplify the process of enrolling in sports organizations and increase the involvement of young people into doing sports $[7,16]$.

Given the popularity of social networks and digital platforms, the development of applications with online training, organization of mass races, training diaries will significantly increase the involvement of the population in the development of physical fitness [2]. According to Sensor Tower, various applications for online sports classes download from 100 thousand to 2 million users every month (

Fig. 1) [11]. 


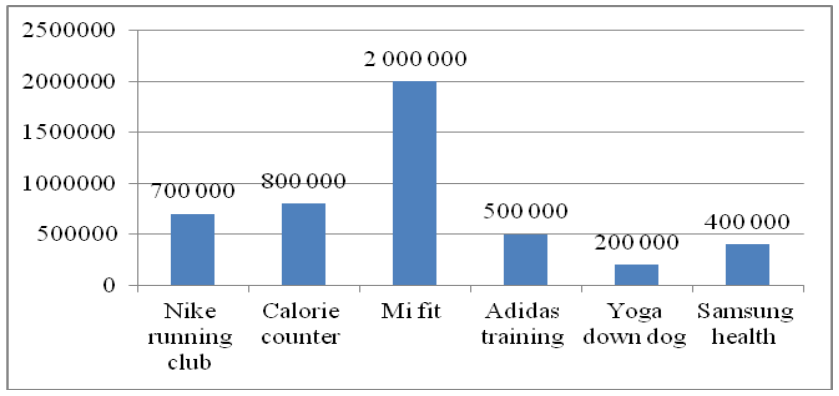

Fig. 1. The number of downloads of sports applications in February 2021 (according to Sensor Tower).

Also, the use of gadgets and specialized programs is gradually introduced in higher education institutions [6]. Let's consider the practice of using them in two leading universities in Russia - the federal state autonomous educational institution of higher professional education "First Moscow State Medical University named after I.M. Sechenov" Ministry of Health of Russia and Moscow State Technical University named after N.E. Bauman. The competition for students was held between two higher educational institutions in terms of activity with additional diagnostics. The goals of the competition were: increasing the motor activity of students, involving young people in a healthy lifestyle, digitizing the student self-control diary.

According to the results of innovations in these universities, there was an increase in the overall activity and working capacity of students in conditions of increased physical activity (67\% of people), more than half of the participants $(58 \%)$ began to control diet using an electronic nutrition diary [13].

During the period of self-isolation, physical education occupation using digital devices became a reality. In most Russian universities, classes were read to the student on the basis of recorded video materials of the program [6]. Also, in the didactic materials of the new generation, multimedia tools are widely used - sound, video, animation [4, 12].

While in Russia the key initiatives have the state support, in the western countries it is possible to note active development of the private companies. An excellent example of that - MLBAM (Limited liability company of owners of clubs of the Highest baseball league). Created in 2002 as limited partnership between clubs of MLB, these owners of the digital rights quickly became famous as the example of innovations, best in the class. Having developed leading baseball solutions, the company took over the creation of all the digital properties of the NHL in 2015, including website, mobile applications, operations and the distribution of digital streaming service in the United States. Technologically progressive initiatives brought impressive amounts - the company concluded a deal for $\$ 600$ million. BAMTech, MLBAM's technology subsidiary, in which the NHL was also a shareholder, invested $\$ 2.58$ billion in a $75 \%$ stake in 2017 [14].

\section{Discussion}

Thus, currently there is a development of digital innovations in sports industry. The prerequisites for this are the development of "Strategies for the development of physical culture and sports for the period until 2030" [15]. The decision to introduce an open ecosystem of digital platforms, which combines all services for government, citizens and the business of the sports industry, contributes to the formation of a service-oriented model for managing the sports sphere. 
For Russian citizens registered in the "Gosuslugi" system, the personal National Sports Rating (NSR) will allow taking into account their activity in physical education and sports, participation in sports events, and will monitor their health.

In turn, it is necessary to note the high demand for online sports services. Especially during the COVID-19 pandemic, when most of people were forced to adhere to selfisolation, significantly increased the audience who downloaded mobile applications with online training, as well as watching broadcasts of fitness bloggers on Instagram. This factor served the development of streaming services. According to the statistics of application stores indicated in the "Results" section, the number of downloads of popular applications for sports is from 100 thousand to two million per month.

However, the formation of physical training of young people takes place more in educational institutions of different levels. Physical education classes are implemented on classical, checked by time, but quite conservative system. Is it possible to move from traditional physical fitness testing systems to digital ones?

Theoretically and technologically, this is possible, and was demonstrated by the labor collective Kukushkin A.A., Novoselov M.A. [8]. The evaluation model they created showed the possibility of digitized registration of physical and theoretical, psychological readiness (tests were sewn into the pop-up menu of the sensory visualizer) [8]. Attempts to implement this model in practice have shown that in the sports field there are no regulatory acts for the implementation of this project, since there is no document fixing the possibility of using sensory regulators in physical culture and sports lessons.

Involving young people in physical education and sports classes is the main task of digital transformation. The formation of a modern digital educational environment would allow the implementation in the regions of Russia of a model of continuous education that would positively affect the educational migration of the best students through network education and interaction, would help prevent the outflow of the most talented youth to other regions.

In many ways, the development of projects based on information technologies owes the support of the Ministry of Sports. Its priorities have been implemented in the spring of 2021. According to the results of innovations, at present, applications of participants for sports events of different levels are submitted in an online format, and are processed using specialized online services that are integrated with official registries of sports federations [10].

These results show the general vector of digital transformation of the physical culture and sports industry, the advantages of information technologies, data analysis services, streaming platforms. This, of course, will make classes sports more accessible, and the entire industry - progressive. Among other things, the experience of Western companies confirms the high profitability of implementing digital innovations.

\section{Conclusion}

The obtained results allow us to formulate the following theses:

- The creation of regulations will serve as an impetus for the use of digital technologies in the field of physical culture and sports in order to increase physical development;

- Increased investment (including by the state) in the physical culture and sports industry will serve as a favorable ground to create digital projects for the provision of sports and sports services;

- Digital technologies can help automate and simplify data-intensive information collection [5, 9]; 
- Taking into consideration the popularity of applications for sports, we can conclude that there is a high need for the use of digital technologies;

- The use of digital applications can increase human physical activity (on the example of students of the First Sechenov Moscow State Medical University and Bauman Moscow State Technical University);

- Employment of digital technologies for selling tickets and booking seats for sporting events in the online format will become a significant simplification of the ticketing procedure, ensure timely monitoring and safety of sporting events;

- The use of digital new online solutions by sports public (state) organizations will make it possible to summarize and analyze the results of athletes, the level of their sports training in a short time. And it will also increase the transparency of sports results;

- The use of digital technologies by sports commercial organizations will improve the quality of service and make sports classes more accessible, which will lead to increased profits.

\section{References:}

1. A.O. Aleksina, D.V Chernova, A.Y Aleksin, Digital Transformation of the Economy: Challenges, Trends and New Opportunities, 908, 703 (2020)

2. A.O. Aleksina, D.V Chernova, L.A. Ivanova, A.Y. Aleksin, M.N Piskaykina, Perspectives on the use of New Information and Communication Technology (ICT) in the Modern Economy (Advances in Intelligent Systems and Computing), 726, 473 (2019)

3. Edinaya cifrovaya platforma «Fizicheskaya kul'tura i sport» nachnet rabotat' v 2021 godu, http:// cnews.ru/link/n523101, last accessed 2021/03/10.

4. A. Goldfarb, C. Tucker, Journal of Economic Literature 57(13), 3-43 (2019).

5. H. Haini, Applied Economics Letters 26(21), 1774 (2019)

6. O.A. Kazakova, L.A. Ivanova, V.S. Martynenko, Lecture Notes in Networks and Systems, 133, 377 (2021)

7. Kejsy cifrovoj transformacii regionov, https://dataeconomy.ru/regions?s_recid=178580496\&s_charact\%3A216653=Fizichesk aya+kul'tura+i+sport, last accessed 2021/03/03.

8. A.A. Kukushkin, M.A. Novoselov, Collection of works by students and young scientists of FSBEE HE «RSYPCSY\&T» material of scientific conferences among students and young scientists, (Bauman Russian State Pedagogical University, 2014)

9. V.V. Mantulenko, Current Achievements, Challenges and Digital Chances of Knowledge Based Economy, 133, 581 (2021)

10. Minsport nazval pyat' prioritetnyh zadach cifrovoj transformacii otrasli na blizhajshij god, https://d-russia.ru/minsport-nazval-pjat-prioritetnyh-zadach-cifrovojtransformacii-otrasli-na-blizhajshij-god.html, last accessed 2020/05/25.

11. Sensor Tower, https://sensortower.com, last accessed 2021/03/03.

12. A. Shestakov, E. Noskov, V. Tikhonov, N. Astafeva Russia and the European union: development and perspectives, 327 (2017)

13. E.N. Skarzhinskaya, E.V. Sarafanova, FICEHS-2019, 114, 805 (2019)

14. Sports industry: time to refocus? PwC's Sports Survey 2019, https://www.pwc.ch/en/insights/sport/sports-survey-2019.html, last accessed 2021/03/03. 
15. Strategies for the development of physical culture and sports for the period until 2030 , https://medium.com/digital-sports, last accessed 2020/03/08.

16. V bazu effektivnyh kejsov organizacii «cifrovaya ekonomika» vklyucheno 10 cifrovyh reshenij $\mathrm{v}$ sfere fizicheskoj kul'tury i sporta, https://minsport.gov.ru/presscentre/news/35444/, last accessed 2020/11/16. 